\title{
Problems in Scientific Research
}

\author{
Mostafa. Abdel-Nasser ${ }^{1}, \mathrm{PhD}$
}

\section{Editorial letter}

*Corresponding Author:

Mostafa. Abdel-Nasser

mostafa_online1@yahoo.com,

mostafa.nasser@azhar.edu.eg

Received for publication January 1,

2021; Accepted Feb. 18, 2021;

Published online Feb. 18, 2021.

Copyright 2020 The Authors published by Al-Azhar University, Faculty of Medicine, Cairo, Egypt. All rights reserved. This an open-access article distributed under the legal terms, where it is permissible to download and share the work provided it is properly cited.

\section{Doi: $\quad$ 10.21608/aimj.2021.56155.1391}

${ }^{1}$ Professor of Microbiology \& Immunology Faculty of Medicine, AlAzhar University,

\begin{abstract}
Scientific research faces many problems and obstacles especially in developing countries. So, from the early beginning, if we start with a problem, then ways and methods will also be accompanied by obstacles which may lead to more complications. The aim of this study was to clarify some of the most important problems in the field of scientific research in our organization and to suggest solutions for them. Some of these research problems are addressed as follows: 1) is there a difficulty in choosing the research topic? 2) is the topic common or rare? 3) is the research proposal approved from the ethical committee? 4) which material and methods will be used? 5) how can we interpret our results? 6) are references available? 7) where does the financial support come from?8) will this work be done in a team? 9) where are we going to publish this research?, and 10) how shall we apply our research? To achieve the goal of certain research, we should spend more times in choosing our research topic and to allocate our resources particularly if they are limited. Again, working in a team and surely, applying our results will help more and more in solving many research problems.
\end{abstract}

Key words: Scientific; Research; Problems.

Disclosure: The authors have no financial interest to declare in relation to the content of this article. Editorial letter

Authorship: Single Author

\section{INTRODUCTION:}

Scientific research faces many problems and obstacles especially in developing countries. If we remember that research was originally designed to solve some problems or to investigate certain phenomenon, these will add more difficulties. Research may start from the point of thinking of how to solve certain limited, local, national, regional or international problem. When solving a problem another one may arise, and research will continue and so on (Figure 1). The aim of this study is to clarify some of the most important problems in the field of scientific research in our organization and to suggest solutions for them. Now what are the problems which may face researchers not only in our organization, but may be in other research organizations and institutes in the developing countries? Some of these problems are formulated in the following questions (Table 1):

1) is there a difficulty in choosing the research topic?

2 ) is the topic common or rare?

3 ) is the research proposal approved from the ethical committee?

4) which material and methods will be used?

5) how can we interpret our results?

6) are references available?

7) where is the financial support come from?

8 ) was this work done in a team?

9) where are we going to publish this research?

10) how to apply our research?
The idea of this topic went back to 2001, when we have launched the training courses of the university teacher in the Faculty of Medicine, Al-Azhar University by the Medical Education Unit. This topic was chosen as one of the essential topics within the lectures of the training course.

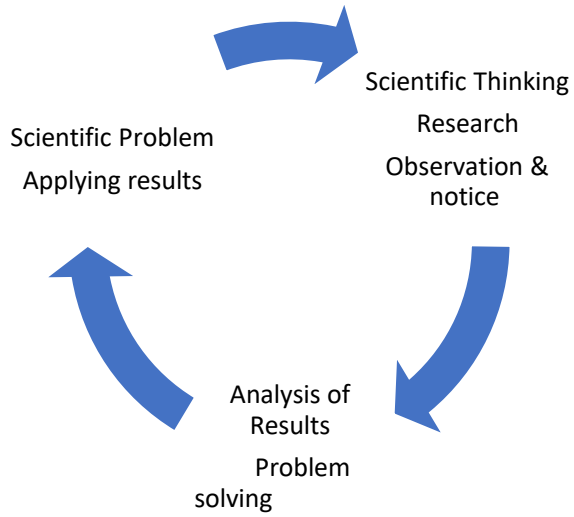

Fig. 1: Research circle.

Table 1: Problems of scientific research: 
1) Choosing the research topic:

Research point may be either of academic interest (master or doctorate theses) or applied interest (e.g., field study). However, both type of research may be carried at once. Most of academic research done for promotion to a higher degree. Sometimes research is not applied or may be difficult to be applied. On the other hand, researcher may choose a topic which has been tackled many times. Applied research aims to solve certain problem facing community or organization sponsoring this research. Some organizations invite researchers working inside or outside to share in solving certain problems like looking for a new drug for treating certain disease or designing a new method for detecting certain microbe or antibodies reacting with a microbe. Academic/applied research usually indicates researches done in universities and research centers.

The following solutions are recommended to solve this problem: a) Feasibility study regarding its importance and applicability before registering or launching a research point. The study should include requirements and expenses of this research b) Researcher should be aware of knowledge regarding his research point (scientific rehabilitation), through an introductory study related to his major and minor specialty, c) Supervisors should have enough knowledge regarding the research point and the availability of doing such research inside or outside his country if this indicated. d) Organization should believe in the importance and value of this research otherwise its continuity and support will be interrupted, e) Cooperation between universities and research centers in such a way to solve an urgent environmental issue like hospital infection or epidemiological issues like hepatitis $\mathrm{C}$ virus infection and so on, and f) A pilot study should be carried out to pro-cast what will be found in this study. This will add or delete some experiments if required.

\section{2) Rare or Common topic:}

In fact, rare topic may be a weapon with two ends. But how is this? Researcher may find many difficulties to know the size of this research problem, how to choose methods of his experiments, analyze or present his results. References related to this topic may not be found and if found they may not be enough to detect this problem or to help in analysis of data and comparing them with those of others. An example of this is an investigation of the genetic structure of a rare or newly discovered microbe. On the hand if the researcher, for example uncover the genetic code of one virus or methods of its control in or outside the human body, he will be the first one to do this in this field. Common topic will make research an easy one beside its ease in analysis and comparison of data with others. Nevertheless, in many cases, research may be useless, if it is at the end, just a repetition of what has been done before without adding more.

Now what are the recommended solutions to overcome this problem? For a rare topic: an extensive study should be carried out before the researcher launches his experiments and after he had consulted experts in that field. For a common topic: a feasibility study should be carried out to show the value of repeating a topic which had been done before. If there is an urgent need found by the researcher because of the changing of place, time and other things like environmental, social and health factors he will carry on.

\section{3) Ethical Consideration:}

The most important item in doing research is to think and ask yourself; is this work ethical or not?. What happens, is that some researchers may neglect, deny ethics of research or on the best of their knowledge do not have an idea about this issue. So, they start collecting their data without telling patients (for example) that they themselves or others may get a benefit in the future. Again, researchers may do a lot of harm to experimental animals without doing some effort to lessen pain. Nowadays, our environment may be affected or contaminated with a lot of waste products, without taking into consideration that this will come back to us.

In this regard, researcher should consult ethical committee in his organization during designing his research, in the following issues: choosing to test and control groups, nature of the study, tacking consent, and other new coming issues regarding patients, lab animals and environment. He should also refer to national and international regulations in the area of his research. However, Vose and Cervellini ${ }^{1}$ (1981) stressed on improving the relative status of scientists, choosing rational and useful research projects.

4) Materials and Methods:

Materials e.g., patients, experimental animals, microbial strains, chemical etc., represent a certain problem if they are deficient or not available Quantity represents a problem if there are few or rare materials. Quality may also represent difficulty in differentiation and classification of research cases. Before launching experiments, researcher should take care of the availability of some or either of the following materials: a) study group (patients and their control), b) experimental animals with their feeding and living conditions, c) microbial strains included in his research with good communication with other organizations and scientific centers supplying them, and d) equipment, chemical and kits required for his study. Methodology is addressed in the form of a) methods' manual; which depends on instructions done by other scientists and collected in this manual; any errors in applying them may affect the quality of his results, b) measuring equipment may has some problems in calibration or maintenance. Sometimes, they are either expensive or not available. Again, automated machines may need a good training, c) quality control/quality assurance (QC/QA); non using of positive and negative control groups, standards or calibrators for patients, experimental animals and machines will make results too difficult to be compared with reference values or those of others, and d) other factors; including physical (e.g. electricity), chemical (e.g. changes in $\mathrm{pH}$ ), environmental (e.g. changes in temperature) or biological (death of some laboratory animals) conditions, may the affect the research process and the validity its data.

To overcome and safeguard a problem like that: a) researcher should be aware of his research methods and their references. Manuals and leaflets for preparation of materials and compounds included in his research should be available and carefully followed, b) researcher should be aware of how his machines and equipments are working and how to fix them if it is convenient, c) He should include control groups for patients, experimental animals or other samples, d) He should also use calibrators for his machines and equipments and share in external quality control program, and e) physical, chemical, environmental and biological factors should also be taken in consideration. Expiry dates of chemicals should also be noticed.

\section{5) Results and Discussion:}

The researcher's goal is to gain a fruitful result. However, he may find that what he has gained whether positive or negative findings are invaluable, especially in the field study. Again, if the researcher is not having a good knowledge in his specialty and other basic sciences related to this specialty, principles of statistics and modern technology, he will face many difficulties in interpretation of his data.

So, to safe guard against these problems, the following may be valuable: a) researcher should be accurate and onset in transcription of his data, b) $\mathrm{He}$ should give an attention for negative like positive data, c) He should also be aware of the methods of data collection and data entry and their presentation using Microsoft office program, for example d) researcher should be aware of the principles of statistics, e) He should know how to tabulate his data and clarify them in figures and diagrams, f) $\mathrm{He}$ 
should make a comparison between test and control groups with reference to their statistical value, g) He should also compare his data with others, stressing on what is similar and what is different and why?, h) He should make a summary and conclusion of what he has and what he has not been achieved, and i) Finally, he should make a recommendation for further study for those which have not achieved.

\section{7) Financial Support:}

In fact, this issue represents an important, viable and sensitive part of research and it should be tackled cautiously to achieve research.

To get a benefit from or looking for a financial support, the following is recommended: a)researcher may apply to the scientific committee in his university or organization for a total or partial financial support or grant, b) researcher may be in contact with some organizations interested in his research like pharmaceutical companies, c) He can do his research through a joint supervision or scholarship sponsored by the ministry of higher education or through a link with a foreign university or other scientific organization, abroad, d) He may work through some research projects interested in his topic, like projects for control of Bilariziasis or cancer, and e) $\mathrm{He}$ can also choose a topic directed towards solving environmental and community problems like hospital acquired infection or liver diseases. In this regard, Badr $^{2}$ (2018), stated that an investment in scientific research may prove to be the key to solve many of these other daunting chronic problems.

\section{8) Teamwork:}

Research should be done in a teamwork who cooperate in such a way to finish their work smoothly, especially in research which include different specialties or more than two persons. Sometimes, most of the work done by one researcher or he is the only one who do the work and others just add their names. Likewise, some supervisors of master or doctorate theses leave the candidate guided by only one of them or even without. Again, the candidate, being a junior researcher, may find himself do a lot of investigation with no great value for his research and with more time and effort.

To overcome these problems, it is advisable that research teamwork should smoothly cooperate to get a more benefit from their specialties, experiences and interest. No one should be chosen for supervision of a thesis, unless he has an idea about the type and size of work and time frame to finish. The team should also meet regularly to evaluate their achievements. Voce and Cervellini $(1981)^{1}$ suggested that special encouragement of exciting effective research groups and concentration of farcicalities rather than requiring massive additional expenditure. Motivation and effective learning and training are also to be considered.

\section{9) Publication:}

Publishing a research aims at telling others what you have achieved. Researcher may be publishing in a specialized or nonspecialized scientific journal. Publishing in a journal with multiple specialties may attract multidisciplinary scientists while specialized journal may attract only scientists in one or related specialty. Researcher publishing in general (nonspecialized) journal (e.g., Journal of Medicine) may find a lot of people to know his achievement while they may underestimate his work. Researcher who will publish in specialized journal (e.g., Journal of Immunology, Virology, Reproduction and so on) may find some people in his specialty who will appreciate his work.

To overcome such a problem, the researcher may follow these recommendations: a) choosing specialized or non-specialized journal according to the nature of research and the interest of other researchers in his field, b) choosing a specialized journal, if his research includes a highly sophisticated methodology which will be difficult for non-specialists to understand, and c) Nowadays, open access journals are more widespread and available on the website. They have an advantage of making our research available to many scientists. Moreover, many international journals are highly targeted as they are indexed in one or more of international organizations as Scopus or Clarivate with multiple databases.

\section{0) Application of Results:}

Finally, researcher may be frustrated when he finds his research left on the shelf of the library of his organization where no one even junior researcher looks at. In the best situation researcher may find his work started to be applied, then it was stopped for some difficulties found during application or for no reason. Sometimes he may not be asked to share in its application. Now how can we overcome these problems?

a) organization's library can make an index for scientific papers and theses according to their authors or subjects for easy refer to, b)they can also keep all these on CD for easy data retrieving, c) abstracts can be published on the organization web site with biography of the researcher, d) rewarding researcher whom research can be applied, e) encouraging researcher to apply his work and give him a moral and financial support or nominate him for international or national prize, $f$ ) encouraging researcher to continue his research in the same point (if there is a need), g) helping researcher in marketing his research in other organizations like industry, drug companies, etc., in such a way to help him in solving environmental, health and other community problems. Aedh and Elfaki ${ }^{3}$ (2019) suggested the two keyways to encourage strong research studies would involve rethinking the reward system and building more transparency into the research process beside getting ways to increase grants for running the costs.

\section{Conclusion:}

To achieve the goal of certain research, we should spend more time in choosing the topic of our research, to think whether this research is ethical or not and to allocate our resources particularly if they are limited. Again, working in a team and surely, applying our results will help more and more in solving many research problems.

Conflict of interest statement: Nothing to disclose.

\section{REFERENCES}

1. 1. Vose PB and A. Cervellini A (1981). Problems of scientific research in developing countries, Technical co-operation IAEA. Bulletin. 1981; Vol.25, No. 237, 37-40.

2. 2. Badr MZ. Challenges facing scientific research in developing countries, 2. Environment and resources. Egyptian Journal of Basic and Clinical Pharmacology, 2018; Vol.8, Article ID 101378, 1-2.

3. 3. Aedh A and Elfaki NK (2019). Challenges confronting scientific research, A systematic review. International Egyptian Journal of Trend Scientific Research and Development (IJTSRD), Vol.3, Issue 4Article ID 101378, 1-3. 